BMJ Open Sport \& Exercise Medicine

\title{
Low fitness, low body mass and prior injury predict injury risk during military recruit training: a prospective cohort study in the British Army
}

\author{
Mark Robinson, ${ }^{1,2}$ Andrew Siddall, ${ }^{2}$ James Bilzon, ${ }^{2}$ Dylan Thompson, ${ }^{2}$ \\ Julie Greeves, ${ }^{3}$ Rachel Izard, ${ }^{3}$ Keith Stokes ${ }^{2}$
}

To cite: Robinson $\mathrm{M}$, Siddall A, Bilzon J, et al. Low fitness, low body mass and prior injury predict injury risk during military recruit training: a prospective cohort study in the British Army. BMJ Open Sport Exerc Med 2016;2: 000100 .

doi:10.1136/bmjsem-2015000100

- Prepublication history and additional material is available. To view please visit the journal (http://dx.doi.org/ 10.1136/bmjsem-2015000100).

Accepted 1 January 2016

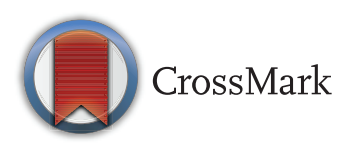

${ }^{1}$ Public Health Science Directorate, NHS Health Scotland, Glasgow, UK 2Department for Health, University of Bath, Bath, UK ${ }^{3}$ Department of Occupational Medicine, Headquarters Army Recruiting and Training Division, Upavon, UK

Correspondence to Dr Keith Stokes; k.stokes@bath.ac.uk

\section{ABSTRACT}

Background: Injuries sustained by military recruits during initial training impede training progression and military readiness while increasing financial costs. This study investigated training-related injuries and injury risk factors among British Army infantry recruits. Methods: Recruits starting infantry training at the British Army Infantry Training Centre between September 2008 and March 2010 were eligible to take part. Information regarding lifestyle behaviours and injury history was collected using the Military Pretraining Questionnaire. Sociodemographic, anthropometric, physical fitness and injury (lower limb and lower back) data were obtained from Army databases. Univariable and multivariable Cox regression models were used to explore the association between time to first training injury and potential risk factors.

Results: $58 \%$ (95\% Cl $55 \%$ to $60 \%$ ) of 1810 recruits sustained at least 1 injury during training. Overuse injuries were more common than traumatic injuries (65\% and $35 \%$, respectively). The lower leg accounted for $81 \%$ of all injuries, and non-specific soft tissue damage was the leading diagnosis ( $55 \%$ of all injuries). Injuries resulted in 122 (118 to 126) training days lost per 1000 person-days. Slower $2.4 \mathrm{~km}$ run time, low body mass, past injury and shin pain were independently associated with higher risk of any injury. Conclusions: There was a high incidence of overuse injuries in British Army recruits undertaking infantry training. Recruits with lower pretraining fitness levels, low body mass and past injuries were at higher risk. Faster $2.4 \mathrm{~km}$ run time performance and minimal body mass standards should be considered for physical entry criteria.

\section{INTRODUCTION}

The high physical demands of military training are associated with a high-risk of training-related musculoskeletal injuries in personnel. Indeed, musculoskeletal injuries have long been identified as a major problem among military populations, resulting in loss

\section{What are the new findings?}

- This is the first detailed prospective injury risk factor study to be conducted in a UK military recruit population.

- This study has shown a high incidence of overuse injuries in British Army infantry recruits, particularly during the first 6 weeks.

- Recruits with low pretraining cardiorespiratory fitness levels, prior injury and low body mass have an increased risk of training injuries.

How might it impact on clinical practice in the near future?

Pretraining conditioning programmes for less fit recruits and changes to the structure of groupbased training should be considered by military recruiters and trainers.

- Any future changes in the physical entry criteria required for infantry recruits should consider faster $2.4 \mathrm{~km}$ run time and minimum body mass standards.

of training time, reduced performance and, in some cases, permanent discharge. ${ }^{1}$ In an attempt to develop more effective preventative strategies, epidemiological studies have been conducted in various military settings to quantify the scale of the injury problem and to identify the risk factors associated with increased injury risk. ${ }^{1-5}$

Most previous research quantifying injuries during military training has been carried out in the USA. ${ }^{2-5}$ One published study in the UK reported that almost $60 \%$ of 660 infantry soldiers suffered at least one injury during predeployment training, with previous injury and younger age identified as independent risk factors. ${ }^{6}$ Another study found an overall injury incidence of $49 \%$ in British Army 
infantry recruits based on data collected in 2006-2008; however, risk factors were not investigated. ${ }^{7}$ Blacker et $a l^{1}$ examined injuries across different British Army initial training courses and found slower $2.4 \mathrm{~km}$ run time, Caucasian ethnicity and higher/lower body mass index (BMI) to be independent risk factors for training injury. Training establishment attended was also a risk factor for injury. However, only injuries leading to medical discharge were available in the infantry cohort. The authors therefore highlighted a need to accurately quantify injury incidence and injury risk factors among British Army infantry recruits. This is particularly important because infantry recruits perform the most arduous British Army initial training course ${ }^{8}$ and have the highest rates of medical discharge due to training injuries. ${ }^{1}$

The main purpose of this study was to quantify injury rates among British Army infantry recruits during initial training. In addition, a selected number of sociodemographic, anthropometric, lifestyle and fitness characteristics were examined as potential risk factors for injury.

\section{METHODS}

\section{Study design}

A prospective cohort study design was used. Recruits entering the Line infantry, Guards and Parachute regiments who passed an initial Army medical examination and started the Combat Infantryman's Course at the Infantry Training Centre, Catterick $(\mathrm{ITC}(\mathrm{C}))$, UK, between September 2008 and March 2010 were eligible to take part in the study. New intakes of platoons (consisting of $\sim 50$ recruits) start infantry training every 2 weeks, and over the course of this study, recruits in 40 platoons were invited to participate. All infantry recruits embark on 14 weeks of standard initial training (phase 1), followed by 12-14 weeks of trade training specific to their regiment (phase 2). The training syllabus is highly demanding consisting of loaded marching, strength and endurance exercise, weapons handling, self-defence, bayonet fighting, intense tactical field exercises and adventurous training.

Recruits were invited to participate during week 1 of training by a member of Army staff after receiving a full written and oral explanation of the study. Recruits were assured that participation in the study was voluntary and that non-participation would have no influence on training outcome or their military career.

The required sample size in this study was predetermined based on differences in injury incidence between smokers and non-smokers. Using data from Altarac et $a l^{5}$ and taking recruit discharge and dropout into account, it was determined that a minimum sample size of 1030 recruits was required to detect a 0.2 difference in injury incidence between smokers and non-smokers at 0.80 power and $5 \% \alpha$ (two-tailed). During a preliminary study meeting at the Infantry Training Centre, it was advised by Army staff that it would be more meaningful and logistically more pragmatic to ask all recruits entering training over a 1-year period to volunteer as participants. This was supported by the Ministry of Defence Research Ethics Committee. In practice, data collection spanned a total period of 17 months. In accordance with the STrengthening the Reporting of OBservational studies in Epidemiology (STROBE) guidance, retrospective power calculations were not performed. ${ }^{9}$ Where appropriate, statistical precision is indicated by $95 \%$ CIs. ${ }^{9}{ }^{10}$ Ethical approval was obtained from the Ministry of Defence Research Ethics Committee (Protocol number 0805/160).

\section{Measures}

\section{Lifestyle characteristics}

After providing written informed consent, participants willing to take part in the study were asked to complete the Military Pre-training Questionnaire (MPQ). In brief, the MPQ is a reliable self-report instrument specifically designed to assess risk factors for injury among military recruits across five domains: physical activity, injury history, diet, alcohol and smoking. ${ }^{11}$ The questionnaire requested participants' service personnel number (ie, not their name), which was covered and sealed using a protective security strip before submission.

\section{Sociodemographic, anthropometric and physical fitness}

Data on participants' sociodemographic, anthropometric and physical fitness characteristics before training, and on training outcome, were extracted from the British Army's Training, Administration and Financial Management Information System (TAFMIS) by staff members in the Department of Occupational Medicine, Army Recruiting and Training Division (ARTD).

Participants who resided in the UK at selection were assigned an income deprivation score based on their postcode. Postcodes were matched to the smallest geographical area ${ }^{12}$ to which data on the number of people in receipt of key income-related benefits are available. A composite measure of income deprivation was then created to indicate the proportion of the adult population in receipt of income support, job seekers allowance and pension credit benefits. ${ }^{13}$ Income deprivation scores were categorised into quintiles, with ' 1 ' being the $20 \%$ most income-deprived areas of the UK and ' 5 ' being the $20 \%$ least income-deprived areas.

\section{Injuries}

An injury was defined as an event that occurred during training, resulted in damage to the body and for which the recruit sought medical care. Medical staff at ITC(C) record details of all reported injuries incurred by recruits into a computer database. Details included date of visit, diagnosis, anatomical location, number of training days missed, injury outcome and outcome date. Traumatic injuries were defined as those caused by a single abrupt overload of the tissue or joint with sudden onset and usually a known cause. ${ }^{2}{ }^{14}$ Overuse injuries 
were defined as those resulting from long-term energy exchanges resulting in cumulative microtrauma over time. ${ }^{2}$ Data on lower back and lower limb injuries, which account for the majority of all injuries sustained during military training, ${ }^{6}{ }^{15-17}$ were extracted by ARTD staff. Two categories of injury were created: 'any injuries', which included all lower back and lower limb training injuries recorded on the injury database; and 'time-loss injuries', which included all training injuries resulting in one or more days of missed training.

\section{Data analyses}

All statistical analyses were performed using the Statistical Package for the Social Sciences V.19.0 (IBM United Kingdom Limited, Portsmouth, UK). Descriptive analyses were performed on all data related to sociodemographic, anthropometric, physical fitness, lifestyle and injury characteristics. Injury incidence proportion was calculated as:

$$
\begin{aligned}
& \text { Injury incidence }(\%)= \\
& \text { number of recruits with one or more injuries } \\
& \div \text { total number of recruits } \times 100
\end{aligned}
$$

Owing to recruit attrition and because not all recruits completed training, person-time injury incidence rates and new injury diagnosis rates were calculated as:

$$
\begin{aligned}
& \text { Injury incidence rate } \\
& =\text { number of recruits with one or more injuries } \\
& \div \text { total time at risk in days } \times 1000
\end{aligned}
$$

New injury diagnosis rate

( per 1000 person - days)

$=$ total number of injuries

$\div$ total time at risk in days $\times 1000$

For recruits who completed training or were discharged before completing training, time at risk was calculated as:

Time at risk (days) $=$

training completion or discharge date

- ITC(C) start date - days lost due to injury

Cox regression was used to examine the association between the time to first injury (any injury and time-loss injury) and potential risk factors. All continuous variables were categorised to explore possible dose-response associations. ${ }^{9}$ Variables were categorised into quintiles unless there was a more appropriate categorisation based on the data distribution (as was the case for age, smoking status and cigarette pack-years). Some categories of nominal (ethnicity) and ordinal (self-reported physical activity) variables were combined to increase statistical precision. Comparisons between risk factor levels were made using the Wald statistic by comparing the hazard at different levels with a reference level (defined as an HR of 1). Risk factors that were significant at the $\mathrm{p}<0.10$ level in univariable analyses were entered into a backward stepping multivariable Cox regression model with exclusion set at $p>0.10$ enabling independent injury risk factors to be identified. $^{18}$

\section{Missing data}

Trainees who completed the MPQ at the start of the study but had no medical or training data were not included in the study. Not all participants had a complete data set because some data were either missing or identified as erroneous. Missing data analyses were performed to compare injury rates between recruits with and without data on sociodemographic characteristics. No systematic differences were identified. Missing data were therefore assumed to be at random and were handled using list-wise deletion.

\section{Sensitivity analysis}

Sensitivity analyses were carried out to assess the impact of certain assumptions and uncertainties on the robustness of the study results. First, Cox regression analyses were repeated using the forced entry method, entering all risk factors significant in univariable analyses $(\mathrm{p}<0.10)$ into models simultaneously. Second, analyses were repeated using physical fitness data from week 1 of training instead of data from the pretraining selection centre. Finally, data on non-training-related injuries were analysed to enable comparison with those sustained during training.

\section{RESULTS}

\section{Study participants}

A total of 1960 recruits $($ mean \pm SD age, height, body mass and BMI of $20.7 \pm 3.0$ years, $1.77 \pm 0.07 \mathrm{~m}, 70.8$ $\pm 9.8 \mathrm{~kg}$ and $22.6 \pm 2.7 \mathrm{~kg} / \mathrm{m}^{2}$, respectively) completed at least part of the MPQ at the start of the study. The large majority $(93 \%)$ of recruits were of white ethnic origin, and the proportion of recruits who participated in the study were strongly patterned by area deprivation: $32 \%$ of recruits residing in the UK at selection lived in the most income-deprived quintile of areas decreasing steadily to only $10 \%$ who lived in the least incomedeprived quintile. Response rate was unknown as not all incoming platoons were invited to participate. Injury data were available for 1810 recruits, of whom 520 were discharged before completing training (injury-related and non-injury-related discharges).

\section{Descriptive analyses of injuries}

Of the 1810 recruits with medical data, 1045 sustained one or more injuries during training, giving an injury prevalence of $58 \%$ ( 55 to 60 ). There were a total of 1785 injuries over the study period and 1040 (58\% (56 to 61)) of these were time-loss injuries. Time-loss injuries resulted in a median of 24 days $(\mathrm{IQR}=7-71)$ of restricted duties. Most injuries (54\%) occurred in the first 6 weeks of training. 
The most common type of injury was overuse injury, accounting for $65 \%$ of all injuries. The knee $(27 \%)$, foot $(26 \%)$, ankle $(18 \%)$ and shin $(10 \%)$ were the most frequently reported injury sites meaning that the lower leg accounted for $81 \%$ of all reported injuries. Non-specific soft tissue damage was the most commonly reported diagnosis, accounting for $55 \%$ of all injuries $(63 \%$ of traumatic injuries and $50 \%$ of overuse injuries; table 1 ). Muscle strains were the next most common traumatic injury (14\%), while blisters accounted for $19 \%$ of overuse injuries.

After accounting for missing or erroneous data, valid time at risk could be calculated for 1686 recruits. Recruits spent a mean of $186 \pm 84$ days in training, and injuries resulted in 122 (118 to 126) training days lost per 1000 person-days. Table 2 shows the injury incidence and new injury diagnosis rates by injury type.

\section{Injury risk factors}

For any injuries, univariable Cox regression showed that higher injury risk was associated with lower body mass, slower $2.4 \mathrm{~km}$ run time (dose-response association), prior shin pain, previous fracture and injury in the past 12 months (see online supplementary data). With the exception of prior fracture and injury in the past 12 months, the same risk factors were associated with higher injury risk for any time-loss injuries. There was also weak evidence to suggest that current smoking and higher cigarette pack-years were associated with higher risk of training injury.

In multivariable Cox regression analysis, independent risk factors for any injury included low body mass, slower $2.4 \mathrm{~km}$ run time (dose-response association), prior shin pain and injury in the past 12 months (table 3). For any time-loss injuries, evidence was strongest for an association with $2.4 \mathrm{~km}$ run time (dose-response association) and prior shin pain. The survival curves of statistically significant risk factors for any injury and time-loss injuries are provided in the online supplementary data.

\section{Sensitivity analyses}

There were no substantive changes to the results when risk factors were examined by entering risk factors simultaneously into a Cox regression model (see online supplementary data) or when $2.4 \mathrm{~km}$ run time was used from week 1 of training rather than from the selection centre (see online supplementary data). The characteristics of non-training injuries $(n=149)$ were different from injuries sustained during training: $80 \%$ were traumatic compared with only $35 \%$ of training injuries. It was not feasible to explore specific risk factors for non-training-related injuries because of the relatively small number of cases.

\section{DISCUSSION}

\section{Main findings}

This prospective cohort study is the first to provide a detailed systematic analysis of injury rates and associated risk factors among British Army recruits undertaking infantry training. Overall, $58 \%$ of recruits sustained at least one injury to the lower back or lower limb that required medical attention, the majority of which led to time lost from training. The injury incidence rate was 3.5 recruits $/ 1000$ person-days, and the new injury diagnosis rate was 5.9 injuries/1000 person-days. The majority of injuries were non-specific soft tissue injuries, sustained in the knee or foot and categorised as overuse. Slower $2.4 \mathrm{~km}$ run time, low body mass, self-reported injury in the past 12 months and prior shin pain were independently associated with higher injury risk.

\section{Injury incidence}

Although different methodological approaches were used, injury incidence rates among infantry recruits in the present study appear considerably higher than those reported for male non-infantry British Army recruits. ${ }^{1}$ This is consistent with the fact that recruits undertaking infantry training have the highest injury-related medical discharge rate across all British Army initial training courses. ${ }^{1}$ This is unsurprising as the infantry training syllabus is among the most physically demanding initial training course in the British Armed Forces, ${ }^{8}$ meaning recruits have a greater exposure to risk. Indeed, Sharma and colleagues recently reported an injury incidence of $49 \%$ in infantry recruits based on older data than used in this study. ${ }^{7}$ The lower incidence is most likely explained by the exclusion of blisters; if these are excluded from our analysis, injury incidence is also $49 \%$. Variations in injury incidence rates among army recruits in different countries ( 4.1 and $\sim 5.6$ recruits $/ 1000$ person-days in Norwegian ${ }^{19}$ and US $^{2}$ armies, respectively) are more difficult to explain due to differences in training practices, training populations, environmental conditions and injury prevention strategies.

The methodological and analytical approach taken in this study was similar to that described by Wilkinson and colleagues, who investigated injuries among trained British Army infantry soldiers. ${ }^{6}$ The authors reported injury incidence and new injury diagnosis rates (1.6 and 2.4 recruits $/ 1000$ person-days, respectively) that were less than half of those reported for infantry recruits in the present study. The higher recruit injury incidence rate in this study is likely due to recruits' intense and concentrated training regime, lack of training experience and a lower level of physical fitness than trained soldiers. ${ }^{20}$ This is supported by the fact that the majority $(65 \%)$ of all training-related injuries in the present study were classified as overuse compared with only $17 \%$ in trained infantry soldiers. ${ }^{6}$

\section{Injury risk factors}

Identifying risk factors associated with injuries is crucial for developing prevention strategies. Consistent with previous studies involving run distances ranging from 2.4 to $3.2 \mathrm{~km},{ }^{12}$ we found that slower maximal effort run time was a significant independent risk factor for injury 
Table 1 Distribution of all injuries by anatomical location

\begin{tabular}{|c|c|c|c|c|c|c|}
\hline \multirow[b]{2}{*}{ Diagnoses } & \multicolumn{2}{|c|}{ All injuries } & \multicolumn{2}{|c|}{ Acute injuries } & \multicolumn{2}{|c|}{ Overuse injuries } \\
\hline & $\begin{array}{l}\text { Cases } \\
\text { (n) }\end{array}$ & $\begin{array}{l}\text { Proportion of all } \\
\text { injuries (\%) }\end{array}$ & $\begin{array}{l}\text { Cases } \\
\text { (n) }\end{array}$ & $\begin{array}{l}\text { Proportion of all } \\
\text { acute injuries (\%) }\end{array}$ & $\begin{array}{l}\text { Cases } \\
\text { (n) }\end{array}$ & $\begin{array}{l}\text { Proportion of all } \\
\text { overuse injuries (\%) }\end{array}$ \\
\hline $\begin{array}{l}\text { Non-specific soft } \\
\text { tissue }\end{array}$ & 974 & 55 & 391 & 63 & 583 & 50 \\
\hline Muscle strain & 236 & 13 & 89 & 14 & 147 & 13 \\
\hline Blister & 218 & 12 & 2 & 0 & 216 & 18 \\
\hline $\begin{array}{l}\text { Non-fracture } \\
\text { bone }\end{array}$ & 91 & 5 & 9 & 1 & 82 & 7 \\
\hline Ligament & 75 & 4 & 57 & 9 & 18 & 2 \\
\hline Tendon & 67 & 4 & 6 & 1 & 61 & 5 \\
\hline Stress fracture & 30 & 2 & 0 & 0 & 30 & 3 \\
\hline Laceration & 24 & 1 & 22 & 4 & 2 & 0 \\
\hline Fracture & 27 & 2 & 17 & 3 & 10 & 1 \\
\hline $\mathrm{NFCl}$ & 22 & 1 & 9 & 1 & 13 & 1 \\
\hline Bruising & 16 & 1 & 14 & 2 & 2 & 0 \\
\hline Cartilage & 5 & 0 & 0 & 0 & 5 & 0 \\
\hline Total & 1785 & 100 & 616 & 100 & 1169 & 100 \\
\hline
\end{tabular}

among British Army infantry recruits, with strong evidence of a stepwise association. Despite infantry training being designed to ensure gradual progressions in intensity, this may not manifest in the actual physical demands placed on recruits. ${ }^{8} 21$ Since most tasks during initial military training are conducted in squads, relative exercise intensities may vary widely depending on individual recruit's endurance fitness levels. ${ }^{1}$ The reintroduction of pretraining conditioning programmes for high-risk recruits should remain an important consideration for the British Army. ${ }^{22}{ }^{23}$ Other strategies, such as increasing entry standards, should also be considered.

Prior injury is another injury risk factor commonly reported among military populations. ${ }^{24}$ In the current study, there was a significant association between selfreported injury in the past 12 months, which prevented participation in exercise or sport for longer than a week, and any injury during training, while prior shin pain was

Table 2 Person-time injury incidence and new injury diagnosis rates, by injury type $(n=1686)$

\begin{tabular}{|c|c|c|}
\hline Injury category & $\begin{array}{l}\text { Injury incidence } \\
\text { rate* } \\
(95 \% \mathrm{Cl})\end{array}$ & $\begin{array}{l}\text { New injury } \\
\text { diagnosis rate } \\
(95 \% \mathrm{Cl})\end{array}$ \\
\hline Any injury & 3.5 (3.2 to 3.7 ) & 5.9 (5.6 to 6.2$)$ \\
\hline Traumatic injury & $1.2(1.1$ to 1.3$)$ & 2.1 (2.0 to 2.2$)$ \\
\hline Overuse & 2.2 (2.1 to 2.4$)$ & 3.8 (3.7 to 4.0$)$ \\
\hline $\begin{array}{l}\text { Any time-loss } \\
\text { injury }\end{array}$ & 1.9 (1.8 to 2.0$)$ & 3.4 (3.2 to 3.6 ) \\
\hline $\begin{array}{l}\text { Time-loss } \\
\text { traumatic injury }\end{array}$ & 0.7 (0.7 to 0.8$)$ & $1.2(1.2$ to 1.3$)$ \\
\hline $\begin{array}{l}\text { Time-loss } \\
\text { overuse injury }\end{array}$ & $1.2(1.1$ to 1.3$)$ & 2.2 (2.1 to 2.3 ) \\
\hline
\end{tabular}

*Injured recruits/1000 person-days.

†Injuries/1000 person-days. independently associated with any injury and time-loss injuries. Although it is not clear from this analysis if the injuries reported during training were the same as those previously experienced, it can be speculated that some injuries may have recurred due to premature return to activity, weakened tissues, strength deficits or altered mechanical characteristics. $^{25}$ Recent studies in US recruit populations have found that incomplete recovery from an injury is a better predictor than past injury per se, ${ }^{26-28}$ supporting the inclusion of more refined injury-related questions in pretraining questionnaires.

BMI has been the most frequently reported anthropometrical measure to be independently associated with injury risk, but the findings have been equivocal. ${ }^{1}{ }^{3}$ Although BMI was not associated with injury risk in either univariable or multivariable analyses in the current study, recruits with the lowest body mass were most likely to sustain one or more injuries. Blacker et al hypothesised that the decreased risk of injury among Army recruits with higher BMI in their study may have been attributable to a better ability to cope with load carriage tasks, which are a crucial component of Army training. Although this is a plausible explanation for the higher injury risk among recruits with low body mass observed in the present study, strength test scores before training were not associated with injury. It may be that the strength tests were not specific enough to the physical demands of training. Future investigations should aim to establish if low levels of military-specific strength explain the higher injury risk among recruits with low body mass.

Among the other risk factors explored, cigarette smoking is one of the most consistently cited lifestyle behaviours that increases the risk of musculoskeletal injuries during military training. ${ }^{2}{ }^{5}$ In univariable 
Table 3 Multivariable Cox regression results for any injury and any time-loss injury

\begin{tabular}{|c|c|c|c|c|c|c|c|c|c|c|c|}
\hline \multirow[b]{2}{*}{ Variable } & \multirow[b]{2}{*}{ Level of variable } & \multicolumn{5}{|c|}{ Any injury } & \multicolumn{5}{|c|}{ Time-loss injury } \\
\hline & & $\mathrm{n}$ & HR & \multicolumn{2}{|c|}{$95 \% \mathrm{Cl}$} & \multirow{2}{*}{$\begin{array}{l}\text { p Value } \\
0.01\end{array}$} & \multirow[t]{2}{*}{$\mathbf{n}$} & \multirow[t]{2}{*}{ HR } & \multicolumn{2}{|c|}{$5 \% \mathrm{Cl}$} & \multirow{2}{*}{$\frac{\text { p Value }}{0.15}$} \\
\hline Body mass (kg) & & & & & & & & & & & \\
\hline & $47-62$ & 301 & 1 & & & Referent & 310 & 1 & & & Referent \\
\hline & $62-68$ & 296 & 0.79 & 0.64 & 0.98 & 0.03 & 311 & 0.77 & 0.57 & 1.03 & 0.08 \\
\hline & $68-72$ & 315 & 0.74 & 0.61 & 0.91 & 0.01 & 324 & 0.90 & 0.68 & 1.18 & 0.44 \\
\hline & $72-79$ & 291 & 0.82 & 0.66 & 1.00 & 0.05 & 308 & 1.01 & 0.77 & 1.33 & 0.92 \\
\hline & $79-103$ & 312 & 0.71 & 0.58 & 0.88 & 0.001 & 325 & 0.73 & 0.55 & 0.97 & 0.03 \\
\hline \multirow[t]{6}{*}{$2.4 \mathrm{~km}$ run time $(\mathrm{s})$} & & & & & & $<0.001$ & & & & & 0.001 \\
\hline & $456-575$ & 306 & 1 & & & Referent & 312 & 1 & & & Referent \\
\hline & $575-604$ & 297 & 1.14 & 0.92 & 1.42 & 0.24 & 308 & 1.27 & 0.94 & 1.70 & 0.11 \\
\hline & $604-629$ & 310 & 1.32 & 1.07 & 1.64 & 0.01 & 326 & 1.30 & 0.97 & 1.74 & 0.08 \\
\hline & 629-662 & 308 & 1.32 & 1.07 & 1.64 & 0.01 & 323 & 1.37 & 1.02 & 1.83 & 0.04 \\
\hline & $662-762$ & 294 & 1.60 & 1.29 & 1.99 & 0.00 & 309 & 1.86 & 1.40 & 2.47 & $<0.001$ \\
\hline \multirow[t]{2}{*}{ Prior fracture } & No & & & & & & 857 & 1 & & & Referent \\
\hline & Yes & & & & & & 721 & 1.18 & 0.99 & 1.41 & 0.06 \\
\hline \multirow[t]{2}{*}{ Prior shin pain } & No & 1295 & 1 & & & Referent & 1346 & 1 & & & Referent \\
\hline & Yes & 220 & 1.21 & 1.01 & 1.46 & 0.04 & 232 & 1.55 & 1.24 & 1.94 & $<0.001$ \\
\hline \multirow[t]{2}{*}{ Injury in past 12 months } & No & 1181 & 1 & & & Referent & & & & & \\
\hline & Yes & 334 & 1.19 & 1.01 & 1.39 & 0.03 & & & & & \\
\hline
\end{tabular}

analyses, smoking status and cigarette pack-years were associated with injury risk. However, neither was independently associated with training injury in the multivariable model adjusting for other risk factors. Similar findings were recently reported by Trone et $a l^{29}$ who investigated self-reported smoking as an injury risk factor in US Marine Corps recruits undertaking 12 weeks of initial training. The authors hypothesised that recruits entering more intense training programmes may have inherent characteristics that protect against an increased risk of injury even among smokers. Such residual confounding is a limitation of all observational research, but this would cast into doubt proposed causal mechanisms linking smoking to injury. ${ }^{30}$ Rather, it would imply that smoking is confounded by other factors or is an indicator for other unmeasured confounders.

\section{Strengths and limitations}

This is the first detailed prospective injury risk factor study to be conducted on British Army infantry recruits. The large sample size ensured robust analyses were possible, thereby minimising the potential for spurious associations. This was verified by performing appropriate sensitivity analyses to validate the key findings. Detailed information on a range of potential risk factors was available. This included comprehensive data on lifestyle behaviours, collected using a military-specific questionnaire, which has been psychometrically tested. ${ }^{11}$

The study also had some limitations. The majority of respondents in this study were white and British, which may limit the generalisability of our findings. Nonetheless, as noted previously, the injury risk factors identified are consistent with findings from other military populations. No information was available to assess the circumstances of each injury, which may have revealed additional contextual information to complement our findings. ${ }^{31}$ Also, the most common injuries among infantry recruits were non-specific soft tissue injuries, accounting for over half of all new injuries, and only data on lower limb and lower back injuries were available for analysis. This makes comparisons with injury incidence rates from other populations difficult. More detailed definitions and characterisation of injuries at the outset of the study might have provided more nuanced data and further clarification on the most appropriate preventive strategies and priorities for future research.

\section{CONCLUSION}

In conclusion, this study has shown a high incidence of overuse injuries in British Army infantry recruits. Risk factor analyses indicate that those recruits with lower fitness levels may not be sufficiently conditioned to cope with the arduous demands of infantry training, particularly during the first 6 weeks. Any future changes in the physical entry criteria required for infantry recruits should consider faster $2.4 \mathrm{~km}$ run time and minimum body mass standards.

Acknowledgements The authors would like to express their thanks to the Department of Occupational Medicine at Army Recruiting and Training Division for provision of the injury data, British Army staff at the Infantry Training Centre, Catterick, for their support throughout the study and to all of the study participants.

Contributors MR, KS, JB and DT conceived and designed the study. AS, JG and $\mathrm{RI}$ collected the data. MR analysed the data and wrote the first draft of the manuscript. MR, AS, KS, JB, DT, JG and RI provided substantial contributions to the redrafting of the manuscript. All authors read and approved the final manuscript.

Funding Funding for this work was provided by the Ministry of Defence (Army) Contract number AG1A/1639.

Competing interests KS and DT report receiving research grant funding from the Ministry of Defence (Army); AS reports receiving PhD funding (fees and stipend) from the Ministry of Defence (Army). 
Ethics approval The study had approval from the Ministry of Defence Research Ethics Committee (Protocol number 0805/160).

Provenance and peer review Not commissioned; internally peer reviewed.

Data sharing statement No additional data are available.

Open Access This is an Open Access article distributed in accordance with the Creative Commons Attribution Non Commercial (CC BY-NC 4.0) license, which permits others to distribute, remix, adapt, build upon this work noncommercially, and license their derivative works on different terms, provided the original work is properly cited and the use is non-commercial. See: http:// creativecommons.org/licenses/by-nc/4.0/

\section{REFERENCES}

1. Blacker S, Wilkinson D, Bilzon J, et al. Risk factors for the development of training injuries among British Army recruits. Bristol, UK: Optimal Performance Limited, 2005.

2. Knapik JJ, Sharp MA, Canham-Chervak M, et al. Risk factors for training-related injuries among men and women in basic combat training. Med Sci Sports Exerc 2001;33:946-54.

3. Jones BH, Cowan DN, Tomlinson JP, et al. Epidemiology of injuries associated with physical training among young men in the army. Med Sci Sports Exerc 1993;25:197-203.

4. Reynolds KL, White JS, Knapik JJ, et al. Injuries and risk factors in a 100-mile (161-km) infantry road March. Prev Med 1999;28:167-73.

5. Altarac M, Gardner JW, Popovich RM, et al. Cigarette smoking and exercise-related injuries among young men and women. Am J Prev Med 2000;18:96-102.

6. Wilkinson DM, Blacker SD, Richmond VL, et al. Injuries and injury risk factors among British army infantry soldiers during predeployment training. Inj Prev 2011;17:381-7.

7. Sharma J, Greeves JP, Byers M, et al. Musculoskeletal injuries in British Army recruits: a prospective study of diagnosis-specific incidence and rehabilitation times. BMC Musculoskelet Disord 2015; $16: 106$

8. Wilkinson DM, Rayson MP, Bilzon JL. A physical demands analysis of the 24-week British Army Parachute Regiment recruit training syllabus. Ergonomics 2008;51:649-62.

9. von Elm E, Altman DG, Egger M, et al. STROBE Initiative. The Strengthening the Reporting of Observational Studies in Epidemiology (STROBE) statement: guidelines for reporting observational studies. Epidemiology 2007;18:800-4.

10. Smith $A H$, Bates $M N$. Confidence limit analyses should replace power calculations in the interpretation of epidemiologic studies. Epidemiology 1992;3:449-52.

11. Robinson M, Stokes K, Bilzon J, et al. Test-retest reliability of the Military Pre-training Questionnaire. Occup Med (Lond) 2010;60:476-83.

12. GeoConvert. http://geoconvert.mimas.ac.uk/ (accessed: 20 Jan 2013)

13. NOMIS. http://www.nomisweb.co.uk/ (accessed: 20 Jan 2014).
14. Ekstrand J, Hägglund M, Waldén M. Injury incidence and injury patterns in professional football: the UEFA injury study. $\mathrm{Br} J$ Sports Med 2011;45:553-8.

15. Jones BH, Canham-Chervak M, Canada S, et al. Medical surveillance of injuries in the U.S. Military descriptive epidemiology and recommendations for improvement. Am J Prev Med 2010;38 (Suppl 1):S42-60.

16. Zambraski EJ, Yancosek KE. Prevention and rehabilitation of musculoskeletal injuries during military operations and training. J Strength Cond Res 2012;26(Suppl 2):S101-6.

17. Havenetidis K, Kardaris D, Paxinos T. Profiles of musculoskeletal injuries among Greek Army officer cadets during basic combat training. Mil Med 2011;176:297-303.

18. Machin D, Cheung YB, Parmar MKB. Survival analysis: a practical approach. 2nd edn. Chichester, UK: John Wiley and Sons Ltd, 2006.

19. Heir T, Eide $\mathrm{G}$. Injury proneness in infantry conscripts undergoing a physical training programme: smokeless tobacco use, higher age, and low levels of physical fitness are risk factors. Scand J Med Sci Sports 1997;7:304-11.

20. Davidson PL, Chalmers DJ, Wilson BD, et al. Lower limb injuries in New Zealand Defence Force personnel: descriptive epidemiology. Aust N Z J Public Health 2008;32:167-73.

21. Izard RM, Carter JM, Blacker SD, et al. Progression of the physical demands of a British Army infantry recruit training programme [abstract]. Med Sci Sports Exerc 2007;39:S205-6.

22. Bilzon JLJ, Colclough M, Lowe MP. Influence of preconditioning on British Army infantry training outcome [abstract]. Med Sci Sports Exerc 2008;40:S238.

23. Knapik JJ, Darakjy S, Hauret KG, et al. Increasing the physical fitness of low-fit recruits before basic combat training: an evaluation of fitness, injuries, and training outcomes. Mil Med 2006;171:45-54.

24. Kaufman KR, Brodine S, Shaffer R. Military training-related injuries: surveillance, research, and prevention. Am J Prev Med 2000;18 (Suppl 3):54-63.

25. Whiting WC, Zernicke RF. Biomechanics of musculoskeletal injury. 2nd edn. Champaign, Illinois: Human Kinetics, 2008.

26. Knapik JJ, Graham B, Cobbs J, et al. A prospective investigation of injury incidence and risk factors among army recruits in combat engineer training. J Occup Med Toxicol 2013;8:5.

27. Knapik JJ, Graham B, Cobbs J, et al. A prospective investigation of injury incidence and injury risk factors among Army recruits in military police training. BMC Musculoskelet Disord 2013;14:32.

28. Trone DW, Cipriani DJ, Raman R, et al. The association of self-reported measures with poor training outcomes among male and female U.S. Navy recruits. Mil Med 2013;178:43-9.

29. Trone DW, Cipriani DJ, Raman R, et al. Self-reported smoking and musculoskeletal overuse injury among male and female U.S. Marine Corps recruits. Mil Med 2014;179:735-43.

30. Sale C, Greeves J, Casey AEK. A brief review of the physiological mechanisms by which tobacco smoking predisposes trainees to musculoskeletal injury during initial training. Hampshire, UK: QinetiQ, 2007.

31. Knapik JJ, Grier T, Spiess A, et al. Injury rates and injury risk factors among Federal Bureau of Investigation new agent trainees. BMC Public Health 2011:11:920. 